\title{
Autonomia outorgada e apropriação do trabalho
}

CINARA L. ROSENFIELD*

\section{Introdução}

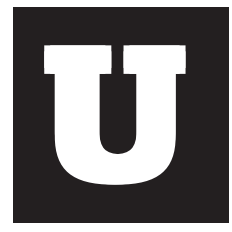

m contexto de precarização e flexibilização do emprego associado a mudanças na organização do trabalho nas sociedades capitalistas impõe um novo padrão de implicação no trabalho por parte do trabalhador industrial. O trabalho produtivo - como padrão, o que não significa a inexistência de trabalho taylorista, precário, penível ou embrutecedor - tornou- se mais variado e mais complexo, o conteúdo e a natureza do trabalho tornaram-se mais ricos, visto uma maior demanda de investimento subjetivo e de mobilização da inteligência. No lugar de tarefas repetitivas e monótonas, o trabalho industrial tornou-se mais instigante, em um contexto de liberalização da situação de trabalho pela outorga de autonomia. Este modelo veio substituir as antigas organizações mais rígidas e formalmente autoritárias. É possível, pois, supor que este quadro represente ganhos para os trabalhadores, já que o trabalho tornou-se mais interessante e as relações de trabalho mais democráticas. O objetivo deste trabalho é discutir o significado desta autonomia outorgada que é o corolário organizacional de uma demanda de mobilização subjetiva. As reflexões aqui presentes estão associadas a um

* Professora do Departamento de Sociologia e do Programa de Pós-Graduação em Sociologia da Universidade Federal do Rio Grande do Sul. 
trabalho de pesquisa empírica junto a trabalhadores da indústria de processo em duas situações: a primeira concerne a uma pesquisa junto à indústria química, na França (Péage de Roussillon) e no Brasil (Paulínia e São José dos Campos), na primeira metade dos anos 90, e culminou com uma proposta de tipologia acerca da relação com o trabalho, com base em 200 entrevistas realizadas nos dois países (ROSENFIELD, 2003a); a segunda refere-se a uma investigação na indústria petroquímica no Pólo Petroquímico de Triunfo (RS), nos anos 2000-1, junto a 40 trabalhadores e seguindo a mesma metodologia, com o objetivo de atualizar a referida tipologia acerca da relação com o trabalho proposta anteriormente (ROSENFIELD, 2003b). No presente artigo discute-se o conceito e as implicações da propalada autonomia no trabalho - industrial produtivo e assalariado ${ }^{1}$-, baseando-nos simultaneamente na literatura - predominantemente francesa - e em nossas observações empíricas, no entanto os dados empíricos não serão explicitamente mobilizados uma vez que nos propomos aqui a uma discussão conceitual, sem dúvida originada nas análises empíricas constantes e explicitadas nos artigos mencionados anteriormente.

\section{Autonomia outorgada e normalização do trabalho}

Ao longo das últimas décadas, a organização do processo de trabaIho sofreu transformações no sentido de uma maior exigência de qualificação e autonomia. Em um contexto de forte competitividade internacional, a empresa confronta-se a imperativos de produtividade e qualidade cada vez mais importantes. A relação com o trabalho e a adesão das pessoas tornam-se fatores de sucesso da empresa, a fim de fazer face a um duplo desafio: aumentar simultaneamente a produtividade e a qualidade de seus produtos e também responder às exigências de flexibilidade e variabilidade

1 Mesmo quando se fala de trabalho de maneira geral, as reflexões aqui presentes limitam-se ao trabalho produtivo industrial assalariado. 
dos produtos. Tornar a produção mais adaptável e mais reativa às exigências do mercado são os objetivos deste "novo modelo de produção" integrado e flexível cuja emergência busca responder aos novos imperativos de "desespecialização" dos trabalhadores e das máquinas, de um trabalho em equipe plurifuncional, da abordagem sistêmica das relações entre as diferentes funções da empresa a fim de controlar o ciclo completo de produção. A nova organização do trabalho deve, pois, fazer face à dinâmica de um conjunto de eventos, concedendo aos operadores uma certa autonomia necessária e desenvolvendo o universo simbólico de inserção à empresa a fim de criar e desenvolver referenciais cognitivos e éticos comuns, assim como zonas de questionamento e de explicitação dos objetivos.

Esta mudança traduz a revisão do modelo organizacional e tecnológico do processo de produção taylorista, caracterizado por: 1) rigidez do apareIho de produção; 2) lógica de especialização e de parcelização das tarefas, que alonga o prazo de produção; 3) crescimento do custo marginal de produção; 4) dissociação da mão-de-obra direta e indireta, freiando o potencial inovador da abordagem sistêmica da produção; 5) limitada qualificação da mão-de-obra gerada pelo próprio dispositivo técnico e organizacional; 6) reação lenta aos problemas de qualidade e às perturbações da demanda cada vez mais heterogênea e instável (ZARIFIAN, 1990).

A empresa busca, portanto, aumentar sua capacidade de reação aos problemas os mais diversos, melhorar a qualidade dos produtos, dispor de meios mais confiáveis, favorecer a flexibilidade da produção e controlar rigidamente os custos de produção. Para alcançar tais objetivos, revela-se necessário um dispositivo organizacional e de gestão das pessoas, que permita aos trabalhadores maior autonomia e responsabilidade, melhoria nas condições de trabalho e de segurança, um trabalho interessante e, ainda, a evolução das competências.

As novas exigências de produção se traduzem por um acréscimo de autonomia, de iniciativa, de responsabilização, de motivação, alcançados 
por métodos que se baseiam na polivalência, no trabalho em equipe, na integração de inteligências e saberes, no direito de expressão, nos controles descentralizados. Os trabalhadores são incitados a se exprimir e a julgar a organização do trabalho a fim de contribuir individualmente com seu saber específico e assim contribuírem para as decisões. Tal proposição, segundo D. Martin (1994), conta satisfazer o trabalhador em termos de: 1) maior interesse pelas tarefas; 2) consideração suplementar que ele acredita gozar; 3) desenvolvimento de sua engenhosidade; 4) alargamento de suas competências; 5) possibilidade de progressão funcional; 6) perspectiva de "auto-atualização" de si.

Promover a participação do trabalhador no processo produtivo visa a implicá-lo no processo, a integrar sua contribuição pessoal ao trabalho prescrito de maneira transparente. Participar significa contribuir de maneira aberta e explícita, integrando o informal à regra desde que signifique o aperfeiçoamento desta. Ora, a autonomia outorgada aos trabalhadores visa reduzir a margem de criação e de improvisação para dar lugar a um sistema de gestão normativo, em que a autonomia real deva integrar-se à institucionalização da autonomia. A autonomia real é a iniciativa tomada, é a criação e o poder de decisão ante uma situação imprevista. E ela existe sempre, mesmo se todos os esforços hoje se orientem em direção a uma previsão e uma prescrição máximas. No caso de ocorrer, no processo produtivo, um fato imprevisto e extraordinário, o trabalhador toma uma iniciativa no sentido de contornar o problema e garantir o fluxo e a qualidade da produção. Em se tratando de uma iniciativa bem-sucedida, a hierarquia integra-a imediatamente à regra, de maneira a difundir a intervenção e a indicar a todos os trabalhadores como reagir diante de tal imprevisto. O extraordinário deve tornar-se previsível - de maneira a garantir sempre a melhor reação diante do imprevisto no processo de produção - e a criação passa a se inscrever na regra. A autonomia real torna-se heteronomia pois ela se torna uma regra a seguir. Os processos de certificação ISO 9000 prevêem justamente a nor- 
malização máxima do processo produtivo ("escrever tudo o que se faz, fazer tudo o que está escrito"), de maneira a controlar os imprevistos e anular a possibilidade de comprometimento da qualidade e da rapidez. A garantia de qualidade passa pela normalização do trabalho, em que todos devem executar o trabalho da mesma maneira: a melhor, e para tal é preciso integrar o saber-fazer operário. O trabalhador, ao criar uma solução diante do imprevisto, contribui para a normalização das iniciativas a serem tomadas nos casos repetentes. No lugar de uma autonomia real, o que surge é uma autonomia outorgada. A autonomia real remete à criação e à improvisação, enquanto a autonomia outorgada remete à prescrição "os trabalhadores devem ser autônomos", de maneira a inserir o inesperado à regra. Esta deve conter o máximo de previsões e prescrições, para que a ação seja uniformizada e garanta a qualidade do trabalho de todos, ou seja, o operador menos inventivo deve integrar ao seu trabalho a iniciativa tomada pelo operador mais criativo. Assim, a autonomia outorgada remete ao paradoxo em relação à autonomia real, já que a autonomia pode ser compreendida em dois sentidos: o primeiro, em seu sentido positivo, a autonomia real no trabalho que é a autonomia do "fazer bem", que é reconhecido pelos seus pares. Essa autonomia permite proteger-se, uma vez que ela preserva o grupo como base identitária e possibilita um retorno sobre si mesmo capaz de conferir um sentido ao trabalho. O segundo, em seu sentido instrumental, a autonomia é outorgada enquanto instrumento de coordenação das relações de trabalho e visa atingir um objetivo econômico de gestão da empresa. (ROSENFIELD, 2003a).

A autonomia, real ou outorgada, é esta margem de independência em relação ao que foi prescrito, é a iniciativa de decidir e de escolher ou ao menos de influenciar ou intervir sobre o curso da produção. Se, por um lado, constata-se uma tendência à normalização do ato produtivo, por outro, é preciso assinalar que uma certa zona de autonomia está sempre presente. Afirma J.D. Reynaud (1993): 1) não existe instalação automatizada 
que não exija ser pilotada. Há sempre uma margem de imprevistos, de incertezas, de inesperados; 2) as instruções estritas têm sempre uma margem de imprecisão que é coberta pela decisão e iniciativa do executor; 3) existe um processo constante de melhoramento de um equipamento em função das idas e vindas que supõem as lacunas existentes entre concepção e execução; 4) existem regras escritas oficiais e regras não escritas que nascem da própria prática. Desde que estas últimas se tornem coletivas, elas permitem ao grupo constituir-se enquanto tal. As regras efetivas compreendem tanto as regras formais quanto as informais; 5) se a regra efetiva supõe a regra informal, o trabalhador encontra-se confrontado a uma contradição entre a estrita observação das ordens, o que torna a regra informal uma infração, e a necessidade - técnica ou pessoal - de tomar iniciativas. Se o trabalhador corre o risco de decidir a partir de sua experiência e seu próprio saber, opondo-se a uma regra minimamente insuficiente ou incompleta, ele deverá, ou dissimular seu ato de liberdade ou aceitar ver-se desapropriado de seu ato no momento em que este será integrado, pela hierarquia superior, à regra. Um tal movimento sugere uma iniciativa bem sucedida. Mas se ela fracassa, essa iniciativa retorna ao que ela sempre foi: uma infração, e, enquanto tal, passível de sanção.

A partir da questão da evolução da divisão do trabalho, G. de Terssac (1992) desenvolve sua argumentação sobre a noção da autonomia no trabalho. A divisão do trabalho é entendida como especialização que introduz a separação entre os que decidem e os que executam. O autor identifica duas abordagens acerca da análise da função social da divisão do trabalho: 1) a desenvolvida por G. Friedmann (1972) que considera que o sistema de normas e regras operacionais e comportamentais reduz fortemente o grau de liberdade dos indivíduos em suas ações, ou seja, eles são efetivamente influenciados pelos limites impostos; 2) a defendida por J-D. Reynaud (1993), baseada na existência de grupos informais não previstos pela organização oficial e que escapam à racionalização dominante e oficial. Terssac se ins- 
creve nesta segunda abordagem teórica segundo a qual "o indivíduo não está totalmente submetido ao sistema de constrangimentos" (TERSSAC, 1992, p. 32). ${ }^{2}$ Esta última perspectiva permite abordar a questão a partir da existência de regras escritas, ou formais, e de regras não escritas, ou informais. As regras escritas são compostas pelo conjunto de disposições que fixam as normas e limites do trabalho e que: a) devem ser respeitadas, b) são definidas por um grupo visando influenciar o comportamento de outro grupo, c) são elaboradas no exterior do grupo ao qual se aplicam. As regras não escritas reúnem todas as soluções de organização já implementadas e estabilizadas pelos executantes para realizar o trabalho comandado e: a) são decisões comuns a todo o grupo de execução e tacitamente aceitas pelos seus membros; b) constituem uma "irregularidade" aos olhos das regras escritas. Mesmo estando de acordo com a perspectiva teórica adotada pelo autor, parece-nos importante evidenciar dois pontos sobre os quais nossa análise diverge da sua. Primeiramente, as regras escritas - afirma o autor - são elaboradas externamente ao grupo de execução. Em um primeiro momento sim, elas são elaboradas pelo grupo "detentor do saber". Seu saber global e técnico lhe outorga o poder de decisão e de escolha, precedente ao próprio ato produtivo. Mas em nível efetivo, outras escolhas sempre serão feitas porque é impossível enumerar de maneira exaustiva todas as situações possíveis. O operador termina por contribuir com a regra, no momento em que toma uma iniciativa não prevista ou claramente em oposição a ela. Se for eficaz, a iniciativa original passará a integrar a regra. Dito diferentemente, a regra é elaborada no exterior do grupo executor, mas também no seu interior. A questão que se coloca é a da desapropriação de um ato que foi fruto de uma margem de liberdade e/ou audácia. Não se verifica nenhum mecanismo de reconhecimento pela originalidade que virou regra. A regra é impessoal e anônima.

2 Todas as citações traduzidas deste artigo constituem-se de traduções nossas. 
Em nome de uma organização do trabalho mais autônoma, a hierarquia se afastou, e seu antigo papel de agente de reconhecimento do esforço ou da competência individual de cada operário desapareceu. Nenhum mecanismo de reconhecimento substituiu o que era exercido pela chefia. O afastamento da hierarquia foi sentido por muitos como um tipo de abandono. A prova é que muitos operários experimentam a nostalgia de uma chefia forte, mais presente e mais direta. Ela era mais autoritária, mas, em contrapartida, era mais franca e capaz de apoiar o trabalhador quando este necessitasse. A chefia como sustentáculo desaparece - ela assume um papel de condução da dinâmica do grupo - e o trabalhador muitas vezes lastima a perda do chefe duro mas coerente e disponível. O reconhecimento, como afirma Dejours (1995), é: 1) a constatação das insuficiências da organização do trabalho prescrita e dos aportes feitos pelos trabalhadores, individual e coletivamente, no sentido de sua evolução ou de sua eficácia; 2) a gratidão em relação às contribuições sem as quais o processo de trabalho seria paralisado. Ora, quando a inteligência prática é constantemente absorvida pela regra anônima e que a hierarquia direta se afasta e enfraquece seu poder de julgamento, a validade identitária da autonomia é colocada em questão. ${ }^{3}$ Nosso argumento é que a autonomia incita à criação e à liberdade para em seguida integrá-las à norma, o autor desaparece e a criação torna-se regra para o trabalho bem feito - e este é julgado através do produto do trabalho coletivo. Nenhum mecanismo de reconhecimento faz a interface entre a liberdade e a norma.

Seguindo a argumentação do autor, Terssac (1992) caracteriza a regra não escrita como uma decisão comum do grupo de execução e tacitamente aceita pelos seus membros. Concordamos inteiramente com esta afirmação. Em nossas pesquisas empíricas constatamos a existência de acordos

3“É essencial destacar aqui que o reconhecimento não recai sobre a pessoa diretamente. O reconhecimento é indireto, ele é mediatizado pelo trabalho. É o resultado do trabalho o objeto de julgamento e é somente com um retorno sobre si que o sujeito se reapropria desse julgamento para articulá-lo à problemática de sua identidade" (DEJOURS, 1993, p. 50). 
acerca de "infrações", sustentados pelo conjunto do grupo. Esses acordos são a expressão de uma resistência à norma, à obediência e à desapropriação de toda margem de liberdade. Mas existe também o ato individual, sorrateiro, engenhoso que é a expressão de uma liberdade e uma criação pessoal e individual. É um chamado à presença da pessoa do trabalhador no seio de regras que normalizam o trabalho. O trabalho torna-se cada vez mais anônimo já que regido por regras e normas a seguir.

O autor identifica claramente o movimento em direção a ações informais dado que é impossível tudo prever. A autonomia torna-se um elemento técnico de sucesso e seu caráter de transgressão - pelo fato de opor-se às regras - tende a se apagar. A autonomia deve, a partir de então, integrar a regra.

Parece-nos que a legalização das infrações assume um sentido bem particular para os que as executam. Se a infração é um ato de transgressão, de ruptura, sua legalização pode ser uma perda de sentido já que, quando é integrada à regra, o que era violação torna-se ordem a respeitar. Para o trabalhador trata-se da passagem de uma racionalidade objetiva, caracterizada pela busca de autonomia, a uma lógica instrumental caracterizada pela lógica do máximo de eficiência econômica. Desapropriados de uma margem de liberdade, os trabalhadores perdem autonomia real. A autonomia que incitam as chefias é igualmente refutada já que, logo que resulta em algo positivo, ela é destruída como margem de criação e inovação para tornar-se uma regra impessoal comum a todos. A busca por autonomia, enquanto demanda institucional, institucionaliza a criação e a espontaneidade de maneira a aumentar as formas de controle sobre as iniciativas dos trabalhadores. As margens de manobra denotam uma flexibilidade necessária aos esquemas de execução para encontrar soluções originais e cada vez mais eficazes mas, é preciso assinalar, essa autonomia necessária não remete simultaneamente a mais liberdade real. Há um processo contínuo de busca de autonomia e de perda dessa mesma autonomia. 
G. Terssac afirma que a passagem de um universo de regras clandestinas a um universo de regras formais explícitas significa, finalmente, uma perda de autonomia. Fica claro que a busca de autonomia real não se situa necessariamente no interior da lógica da eficiência imediata, mas serve, sobretudo, a atingir o reconhecimento de uma identidade e de uma contribuição e chegar à realização de si. A autonomia se opõe à heteronomia e à necessidade, pois a autonomia de uma atividade marcada pela necessidade é condenada a permanecer formal. A. Gorz (1988) afirma que são autônomas as atividades que são, por elas mesmas, seu próprio fim. O sujeito faz, nessas ações, a experiência de sua soberania e se realiza como pessoa. A autonomia outorgada impõe uma socialização caracterizada pela não-coincidência entre o indivíduo-sujeito e seu ser social; ora, essa coincidência, a partir de então impossível, está na origem da autonomia individual e de toda criação cultural. O indivíduo é condenado a viver a dualidade de ser ele mesmo (l'être-soi) - porque ele precisa ser ele mesmo - e, simultaneamente, responder às exigências sociais do trabalho que demanda "uma maneira de ser ele mesmo" no trabalho (le devoir être). Na realidade, esta dualidade termina por impedir, em parte, de ser ele mesmo (l'être-soi).

Segundo J.P. Durand (2004), merece reflexão o fato de que, hoje, aqueles que dispõem de um emprego formal, mesmo trabalhando muito e/ ou mais que antigamente - seja pela carga seja pelo tempo de trabalho dizem-se satisfeitos com o seu trabalho. O autor cunha o conceito de "implicação constrangida" (implication contrainte) para dar conta deste paradoxo: é preciso maior implicação e investimento no trabalho se os empregados querem mantê-lo, mas, ao mesmo tempo, esse investimento tem recompensas simbólicas em razão do aumento da autonomia no trabalho, da criatividade e da margem de iniciativa que são conferidos ao trabalhador. De nossa parte, trabalhamos com o conceito de autonomia outorgada para dar conta deste mesmo paradoxo (engajamento e adesão aos objetivos da empresa versus obrigação de se engajar), mesmo que o autor contraponha 
o conceito de autonomia conquistada ao de autonomia outorgada. Segundo ele, a autonomia é conquistada na medida em que ela é apropriada pelos trabalhadores, proporcionando uma auto-organização e se fazendo necessária para garantir os objetivos fixados. No entanto, sustentamos que a conquista de uma autonomia outorgada favorece a adaptação e a aceitação por parte dos trabalhadores dos novos padrões de produção, mas não atenua seu caráter de imposição. O paradoxo resultante da contraposição entre a imposição de autonomia e sua apropriação por parte dos trabalhadores lança uma renovação ao fenômeno da alienação do trabalho assalariado. Juntamente com as recompensas simbólicas, as condições de alienação são redobradas pelo mascaramento das relações salariais pela outorga de autonomia, o que reúne as condições daquilo que o autor denomina uma nova servidão voluntária.

\section{Autonomia outorgada é um ganho para o trabalhador?}

Se a autonomia é um método de trabalho concebido para os operários - e não por eles - mas que exige sua mobilização subjetiva, pode ela ser um ganho para os trabalhadores industriais? A questão refere-se ao papel do trabalho nas sociedades capitalistas e às reais possibilidades de tornar o trabalho autônomo, de se apropriar e lutar contra a heteronomia e a alienação.

Falar em autonomia outorgada é apresentar a autonomia como um dom: o trabalhador está novamente em situação de objeto e não de sujeito. A separação entre a concepção e a realização, separação esta colocada em valor pelo taylorismo, é uma separação quanto à relação à linguagem, segundo a tese defendida por Zarifian (1996). No modelo tayloriano, os operários são duplamente excluídos: excluídos da linguagem sobre a organização, ou seja, a linguagem que define a organização e os métodos de trabalho; excluídos também da linguagem dentro da organização, haja vista que os operários não devem ter trocas entre si ou com a hierarquia. É a 
organização que fala deles por intermédio de seu setor de planejamento e métodos, e mesmo quando se procura falar deles como de pessoas - introduz-se crescentemente a psicologia no discurso sobre os trabalhadores, a fim de melhor compreendê-los enquanto sujeitos com seus desejos e afetos próprios -, nada muda quanto ao fato de que quem fala sobre eles não são eles mesmos e que eles permanecem sempre como objeto do discurso e jamais como sujeito da enunciação. Seguindo o raciocínio do autor mas aplicando-o ao nosso objeto, é possível afirmar que a autonomia outorgada pela organização é novamente um método, uma maneira de trabalhar, concebido pelos agentes da concepção para o trabalhador. Excluído da produção da sua própria autonomia, o trabalhador é igualmente impedido de atingir a condição de sujeito, de sujeito da linguagem e de sujeito do ato produtivo. A linguagem legítima é a da direção sobre o "sujeito" trabalhador. A autonomia real, ao contrário, é aquela criada pela constituição do sujeito enquanto sujeito da enunciação, o que significaria uma real mudança em seu status social. Neste momento, o operário abandona seu papel de receptor passivo para falar de si, seu trabalho e seu aporte à organização. A autonomia outorgada, assim, não rompe com o modelo herdado do taylorismo de acesso à linguagem, somente a autonomia real poderia propor uma transformação deste modelo.

Se, por um lado, uma equipe de trabalho pode ser considerada autônoma no momento em que ela dispõe de um certo poder de decisão - ao menos para decidir sobre a melhor maneira de agir para atingir as metas já estabelecidas -, e se, de outro, a lógica institucional caracteriza-se pela forte redução da autonomia do indivíduo, a prática de uma institucionalização da autonomia revela-se de natureza paradoxal. A própria autonomia é já uma ordem e integra uma série de normas que estabelecem a melhor maneira de se trabalhar para garantir a qualidade, a cooperação, as normas de certificação ISO 9000, a reatividade, a participação, o trabalho em equipe, a motivação, o engajamento, etc. As novas regulamentações não resul- 
tam de acordos ou negociações: elas são outorgadas. A autonomia faz parte de uma nova organização do trabalho que instala um processo de institucionalização em que a submissão à regra (e ela preconiza a autonomia!) substitui o acordo entre os indivíduos envolvidos.

Se a autonomia é de natureza institucional e, partindo da hipótese de que o prazer e a realização de si no trabalho encontram-se no espaço criador que se situa entre a regra e a ação, pode-se concluir que esta organização não representa ganho para o trabalhador? De um lado a autonomia preconizada e o enriquecimento do conteúdo do trabalho tornam-no mais prazeroso (o que seria um ganho para o trabalhador), mas, de outro, que sentido conferir à supressão desta margem de liberdade real para a realização de si (e lá o ganho está ausente)? O prazer momentâneo de trabalhar com mais "liberdade", de dominar o trabalho e um maior número de informações é a única maneira possível de viver a privação de um real espaço de liberdade. Daí a seguinte constatação: o que se denomina habitualmente por "mudança cultural" na empresa é uma liberalização da situação de trabalho aliada à complexificação das tarefas, de maneira a apresentá-la como um ganho para os trabalhadores (e talvez o seja), mas sem que signifique um ganho identitário ao nível da realização de si. A mudança cultural, segundo nossas observações empíricas, pode traduzir-se pelo direito de escutar rádio durante o trabalho, de dizer o que se pensa quando se é consultado, de estar mais próximo da chefia, dispor de mais informações, dispor de maior autonomia, usar diferentes e mais complexos instrumentos de trabalho (inclusive os instrumentos de gestão) e trabalhar cada vez mais, a fim de responder a esta nova demanda.

No entanto, este espaço - de criação e de liberdade real - é realmente anulado? Não poderíamos supor, para além deste quadro de autonomia outorgada e de restrições, a emergência e a criação de novas modalidades que permitam preservar uma certa liberdade? Se é possível reconhecer que ações impossíveis de serem previstas sempre existirão e que as diferentes 
interpretações dessas situações são legítimas, não se poderia supor a existência de uma resistência a esta tendência organizacional que visa a suprimir o espaço não preenchido entre regra e ação? Resistência capaz de desenvolver novas formas de relação com o trabalho, a fim de preservar uma certa margem de liberdade e autonomia. E se esta margem não é suscetível de chegar à realização de si, ela pode, ao menos, contribuir a manter uma posição de sujeito por intermédio da resistência. A liberalização significa um clima de liberdade e de autonomia outorgada mas não significa, efetivamente, mais liberdade. Ao contrário, ela acarreta um feito de insegurança pela perda de um referencial real - a autonomia de fato, nãooutorgada - em relação ao qual os trabalhadores constroem sua autonomia. Fazer bem seu trabalho, e fazê-lo corretamente, não mais advém de um investimento autônomo no trabalho.

\section{Apropriação do trabalho e laço social}

A idéia de autonomia no trabalho está relacionada à noção de trabaIho enquanto expressão do homem e local de criação. Para as sociedade fundadas sobre o trabalho, é a partir deste que o indivíduo se reconhece em sua exterioridade e aos olhos dos outros. O trabalho seria o meio de intervir na natureza e de se colocar em relação com o outro. Ele seria capaz de revelar o sujeito a si mesmo e aos seus pares, ele seria a atividade de desenvolvimento e plenitude por excelência, de realização de si e de integração social.

O trabalho como laço social funda-se sobre a idéia de reciprocidade, de contrato social e de utilidade social (MEDA, 1995). A partir de uma contribuição individual, o trabalhador traz uma contribuição que desenvolve seu sentimento de pertencimento em função da utilidade de seu aporte. O trabalho é, para o sujeito, revelador de si mesmo (o que ele é) e da sociedade, e ainda é capaz de transformar o mundo. No entanto, como 
sustenta D. Méda, o trabalho não porta em si mesmo estas funções - estas funções são suscetíveis de serem asseguradas por outros sistemas e, além disso, o significado do trabalho variou historicamente. Se, por um lado, o trabalho é a descoberta de si, expressão de uma individualidade assim que pertencimento ao gênero humano, de outro, nas sociedades capitalistas - e este é o argumento de Marx - o objetivo do trabalho humano não é o desenvolvimento do homem mas o enriquecimento. O trabalho na sociedade industrial capitalista é sempre já alienado pois ele se torna um simples meio de garantir a existência. "O trabalho real é uma abstração sem conteúdo, cujo objetivo é exterior a ele mesmo" (MEDA, 1995:105). Ao invés de atividade essencial, o trabalho como fator de produção e de criação de riquezas é um trabalho alienado. O que o torna alienado é seu fim de servir à acumulação de riquezas, independentemente de seu conteúdo. A racionalidade instrumental que acompanha o capitalismo utiliza o trabalho como meio de atingir um fim que já foi determinado - a riqueza e hoje também a competitividade, esta última se apresentando como a ameaça exterior e contínua capaz de fazer desaparecer a organização -, de maneira que o trabalho termina por ser um fim em si mesmo, como a racionalidade instrumental que "esqueceu" por que ela se instrumentalizou.

O trabalho assalariado, mais que qualquer outro, possui um caráter de subordinação, e o trabalho só pode ser plenitude para os que podem organizar soberanamente o seu próprio trabalho.

A principal característica do trabalho assalariado, que o distingue radicalmente do trabalho independente, é o elo de subordinação existente entre o assalariado e seu empregador, este último deduzindo quase logicamente da natureza do contrato de trabalho. Dito diferentemente, a partir do momento em que se considera que o trabalho humano pode ser objeto de um negócio, esta compra tem como conseqüência a livre disposição daquilo que foi comprado, ou seja, sua direção, no duplo sentido de 'definir os objetivos' e de 'conduzir' (MEDA, 1995, p. 145). 
A autora critica a abordagem marxista que viu as duas primeiras razões pelas quais o trabalho é alienado, a saber a lógica capitalista e a subordinação (o trabalhador deve fazer o que lhe é comandado, da maneira como comandado, em uma organização previamente determinada), sem compreender que estas duas razões se explicam, finalmente, por uma terceira: a vontade de abundância ou de humanização, fundamento do produtivismo. O que significa que o sentido do trabalho hoje é sempre o imperativo da eficiência e que qualquer organização do trabalho será regida pelo princípio soberano de aumentar as riquezas. Eis por que motivo a teoria marxista não fornece os meios de pensar uma verdadeira transformação do sentido do trabalho: a crença no desenvolvimento das forças produtivas impede a compreensão de como tornar o trabalho autônomo mesmo com a apropriação pelos trabalhadores dos meios de produção.

A questão a explorar seria, ainda segundo a autora, de saber se uma atividade pensada a partir do exterior pode ser fonte de expressão de si e de autonomia. Como conciliar subordinação com autonomia e plenitude? É possível lutar contra a heteronomia do trabalho? Existe um trabalho criativo e personalizado na ação formal? Existe qualquer possibilidade de criação e de contribuição pessoal em um ato marcado pela exterioridade? O trabalho imaterial, mas complexo e demandando cada vez maiores competências intelectuais, torna o trabalho mais autônomo?

Méda sustenta que não: o trabalho torna-se menos degradante e demanda novas capacidades humanas mas seria abusivo afirmar que permitiria a expressão e autonomia individuais. A autora enuncia três objeções às análises que acreditam no aumento da autonomia: 1) para que o trabalho se torne nossa "obra" e nosso "meio termo social" seria preciso romper com sua dimensão econômica; 2) se é certo que é quase impossível executar um trabalho durante todo dia sem ali colocar algo de si, quanto à organização, esta deixa pouco espaço para a expressão de si e, quando o faz, é por acidente (ou porque é conveniente, diríamos nós). De qualquer maneira, a verdadeira autonomia e a verdadeira expressão de si consistem em 
"dar a si mesmo a sua própria lei, fixar-se objetivos e os meios de alcançálos" (MEDA, 1995, p. 165); 3) o exagero das teorias que pensam que todo trabalho deve ser "obra", como se todo ato pudesse ser expressão de si. Enfim, sua crítica repousa sobre a concepção do trabalho como obra (ARENDT, 1991) quando, na realidade, é a expressão maior da lógica da eficiência.

Em nossa concepção, se é verdade que o trabalho assalariado nas organizações de tipo capitalista não é autônomo e não permite uma real expressão de si, não é menos verdade que o trabalhador sempre pode encontrar uma margem de criação e autonomia, nem que seja para sobreviver ou para subverter. Nessas condições, o trabalho não é "obra" mas sustentamos que, no mundo do trabalho, o trabalhador se confronta a si mesmo e à sociedade em que vive e que impõe suas regras. A eficiência, que serve mais à organização que ao trabalhador uma vez que ela é inerente ao produtivismo, pode ser fonte de uma certa realização de si desde que seja possível apropriar-se do trabalho. Ou ainda, na crítica ou na negatividade, e mesmo na conformidade, existe a expressão de uma recusa ou de uma lassidão. O trabalho degradante só pode ser vivido experimentando um "vazio" psíquico que permita suportar o sofrimento. A transgressão individual consiste em viver o trabalho como um espaço de confrontação consigo mesmo e com as regras que regem a sociedade. Neste momento, o trabalho pode tornar-se fonte de desalienação. Recusar-se de alguma maneira mesmo continuando a trabalhar como se nada se passasse - ou viver o trabalho em posição de recuo - mesmo que não seja subjetivamente confortável - pode significar uma contribuição à realização de si e uma transgressão para com um trabalho que jamais poderá se tornar "obra".

Além disso, o trabalho contribui essencialmente com o laço social, hoje, porque ele é a principal forma de organização do tempo social e da relação social dominante, e não porque o trabalho esteja no centro da sociedade, já que ela tem outros fins que a produção e a riqueza. A empresa não 
é encarregada de criar uma comunidade política, "destinada a favorecer a plenitude dos indivíduos que ali estão e lhes permitir exercer suas principais capacidades exigidas pela vida em comunidade" (MEDA, 1995, p. 187).

O trabalho, segundo A. Gorz (1988), não pode mais estar na base da integração social, pois a economia não mais necessita do trabalho de todos. Não se trata mais de uma "sociedade de trabalho". Atualmente a ideologia do trabalho consiste em motivar uma parte da mão-de-obra que se revela neste momento dificilmente substituível em função de suas competências próprias, e em controlá-la ideologicamente na falta de poder controlar materialmente. Como? Preservando na mão-de-obra a ética do trabalho, destruindo as solidariedades que poderiam unir os menos privilegiados, incitando a trabalhar o máximo possível para servir a interesses da coletividade e aos seus próprios. Esta integração funcional ao trabalho interdita toda cooperação, a integração social torna-se impossível sem a construção de fins comuns segundo critérios comuns. O núcleo estável no seio dos trabalhadores seria uma elite que ganha com a reorganização do trabalho, em oposição à precariedade do emprego, a insegurança dos outros, o desemprego e a desqualificação. Segundo o autor, o sucesso dessa reorganização supõe relações de confiança e de cooperação entre esses trabalhadores e a direção da empresa. Essa cooperação seria a nova fonte de integração social que diz respeito somente a um número reduzido de trabalhadores. A elite é formada por trabalhadores de um tipo novo: capazes de assumir, no seio de uma equipe polivalente, a condução de uma instalação automatizada; capazes de iniciativas rápidas, capazes de cooperar com seus pares, portadores de autonomia e de sentido de responsabilidade. A organização valoriza psicológica e socialmente esses trabalhadores. Nós constatamos, por nossa vez, em nossa pesquisa na indústria de processo, esta elite bastante reduzida: ela sabe que é uma elite, mas aqueles que fazem parte dela se ressentem da insegurança reinante, assim como de se sentirem "ganhadores" em meio a tantos pares "perdedores". Eles não se sentem realmente 
valorizados, mas, ao menos, guardam a esperança em relação ao seu futuro. Todos os trabalhadores - mantidas as diferentes proporções de implicação no trabalho - procuram responder às novas exigências, sem, no entanto, usufruir de uma real contrapartida por parte da empresa. A integração não é o motor do trabalho e sim a exclusão ou desfiliação segundo o conceito de Castel (1995). Fora da fábrica, o mundo do trabalho pode ser ainda mais degradante, pois mesmo os trabalhadores muito qualificados e portadores de competências valorizadas experimentam o espectro da precariedade do emprego. E esses mesmo trabalhadores prometidos para um futuro promissor exprimem algum ceticismo em relação ao futuro. $\mathrm{O}$ trabalho termina por servir de integração e de laço social não pelo que oferece, mas pela exclusão que representa o não-trabalho. O trabalho é laço social por exclusão.

B. Perret (1988, p. 108) afirma que o trabalho confere uma legitimidade formal ao cidadão e contribui "à qualidade de sua participação efetiva na vida social". Apoiando-se em Durkheim, o autor demonstra que o trabalho é uma forma de coesão social se duas condições forem satisfeitas: 1) a condição de sentido, quando o trabalho faz parte de uma obra comum que ultrapassa o horizonte individual do trabalhador e que ultrapassa sua existência particular; 2) a condição de eqüidade, que significa que o lugar de cada trabalhador na divisão do trabalho deve ser percebido por ele como correspondendo às suas capacidades. O trabalho tem um papel insubstituível no processo de elaboração da imagem de si, e a cooperação resultante da integração pelo trabalho engaja o ator no futuro coletivo. O trabalho participa na construção do laço social, uma vez que ele funda a autonomia social das pessoas. Para o autor, o trabalho humano tende a se especializar justamente por sua especificidade em relação às máquinas. Dito diferentemente, é seu caráter especificamente humano, e portanto mais nobre, que serve de competência insubstituível, a saber: 1) "a capacidade de interpretar uma informação em função da totalidade de elementos do contexto"; 2) "a imaginação, a 
capacidade de inventar novos mundos de inacreditável complexidade"; 3) "a capacidade de entrar em comunicação e em simpatia com seus semelhantes, de conquistar este recurso raro e frágil que é a confiança dos outros" (PERRET, 1988, p. 112). No entanto, o autor salienta que o trabalho humano permanecerá também nas zonas "escuras" dos sistemas mais performáticos: sempre existirá o trabalho "sujo" e manual a fazer, como limpar, desentupir, varrer, introduzir-se dentro dos tubos, etc. Assim, o trabalho inteligente se acompanha do trabalho sem interesse e, às vezes, penível.

No entanto, este elo social prometido pelo trabalho tem um duplo movimento: de integração - quando a ênfase é colocada sobre a mobilização e o engajamento dos trabalhadores -; e de precariedade - quando se trata de redução de custos e de ajustamento da mão-de-obra às novas exigências de produção. Se, por um lado, o trabalho na empresa integra os trabalhadores competentes e motivados, de outro, essa mesma empresa rejeita os insuficientemente produtivos e integrados ao seu projeto. O trabalho integra, mas exclui na mesma proporção (PERRET, 1997).

A atividade produtiva em Marx prefigura transparência da mediação entre o indivíduo e a totalidade social, segundo Perret e Roustang (1993). O trabalho operário, se ele é penível, também está na origem de um sentimento de pertencimento - centrado sobre o lugar de trabalho e sobre a autonomia coletiva ou de classe - em relação à sociedade. A luta de classes permitiria aos mais fracos agregar-se a um grupo social poderoso e reconhecido, por intermédio da constituição de uma identidade profissional, de integração cultural e de participação na vida política. No entanto, a individualização crescente instaura uma solidariedade funcional em que a adesão ao projeto da empresa triunfa sobre as solidariedades de classe.

A empresa diz reconhecer e valorizar cada vez mais a inteligência e as qualidades do trabalhador, ao preço de uma exclusão do mundo do trabalho de um número crescente de trabalhadores. "Tudo se passa como se a exploração mais intensiva do recurso humano tornasse mais difícil uma 
socialização de massa pelo econômico" (PERRET \& ROUSTANG, 1993, p. 77). O social também torna-se excludente.

Um contexto social de "abolição" crescente do trabalho-emprego tem um papel fundamental no individualismo progressivo observado no mundo do trabalho. Como A. Gorz (1997) sustenta, o não-trabalho que, no pósfordismo, podia servir a liberar os indivíduos, terminou por se virar contra eles para lhes despojar e subjugá-los. Como? Abolindo o trabalho mas continuando a fazer dele "a base de pertencimento e dos direitos sociais, a via obrigatória para a estima de si e dos outros" (GORZ, 1997, p. 16). Na empresa pós-fordista, segundo o autor, o trabalho imediato de produção é somente o resultado de uma aplicação material de um trabalho imaterial que supõe a reflexão, a concertação de saberes e de observações, a troca de informações. Quando este processo parecia anunciar a reapropriação do trabalho pelos trabalhadores, a transformação do trabalho em um bem cuja possessão exige sacrifícios e a transformação do emprego em um privilégio culminam em uma sujeição da própria pessoa do trabalhador. Também, sempre segundo o autor, entender a autonomia no trabalho, preconizada pela empresa pós-fordista, como sendo um exercício de autonomia do trabalhador é um "delírio teoricista":

A autonomia no trabalho é pouca coisa na ausência de uma autonomia cultural, moral e política que a prolonga e que não nasce da própria cooperação produtiva mas de uma atividade militante e de cultura da insubmissão, da rebelião, da fraternidade, do livre debate, do questionamento radical (aquela que vai na raiz das coisas) e da dissidência que ela produz. (GORZ, 1997, p. 72).

Em um contexto de desemprego importante e de precarização do emprego, a autonomia no trabalho toma um sentido particular: ter um trabalho autônomo - independentemente de se interrogar sobre os ganhos trazidos - parece secundário a simplesmente ter um emprego. O que signi- 
fica dizer que as exigências colocadas pelo trabalho e suas transformações impõem uma adaptação quase incondicional, sem se colocar realmente a questão da reapropriação do trabalho, o que a priori acompanharia a autonomia no trabalho. A autonomia é outorgada, e não implica necessariamente mais liberdade real nem em investimento pessoal ou apropriação do trabalho.

\section{Considerações finais}

O trabalho vive a contradição entre a apologia da autonomia e uma organização do trabalho crescentemente normalizada. A autonomia preconizada significa se "virar" sozinho quando o trabalho prescrito não é capaz de responder à complexidade do trabalho real. Mas o trabalho não é autônomo, ao contrário, é controlado e obedece a regras muito rígidas. A autonomia proposta pela organização incita a criação para, em seguida, integrála à norma. Tem-se, assim, a despossessão de um ato criador sem que algum mecanismo de reconhecimento faça a mediação entre criação e regra. A autonomia perde seu poder identitário, já que não há um retorno sobre si mesmo. Trata-se de uma autonomia outorgada de natureza alienante que é uma maneira de resolver a contradição entre autonomia e norma. É uma autonomia alienante, precisamente, por seu fraco potencial identitário tendo visto seu caráter contraditório assim que, por sua exigência de inclusão em um universo eminentemente excludente, o que confere ao trabaIhador um estado de servidão - uma servidão voluntária como afirma J.P. Durand (2004).

O conceito de autonomia no trabalho lança mão de duas questões: 1) suas exigências funcionais, operacionais, que remete à organização do trabalho; 2) a busca de afirmação de si, de liberdade, de realização e que remete à sua dimensão identitária. A outorga de autonomia no trabalho é uma mudança de natureza simbólica na organização do trabalho: a decisão 
de outorgar autonomia se toma no nível da gestão dos homens e da produção, mas seu sucesso depende do trabalhador-executor. O êxito da nova organização do trabalho depende do investimento no trabalho do operador e de sua iniciativa a decidir, escolher e influenciar no curso da produção, ou seja, depende do trabalho imaterial. A lógica de avaliação por competência com seu componente comportamental é o meio de controlar a maneira como é utilizada a margem de autonomia concedida aos trabalhadores, de maneira a avaliar sua lealdade e confiabilidade para quem o emprega. Tratase de controle e garantia de atitudes para com o trabalho, a organização e/ ou o empregador (DURAND, 2004).

Na medida em que o sujeito passa a ser mobilizado para a execução do trabalho, pode-se a priori supor que os trabalhadores "ganham" com o enriquecimento do conteúdo e da natureza do seu trabalho. Este ganho pode transparecer através da liberalização da situação do trabalho que vem substituir as antigas organizações mais rígidas e autoritárias. No entanto, estas transformações inscrevem-se integralmente no registro da racionalidade econômica, a despeito do discurso dominante que evoca fins de ordem social e/ou subjetiva.

A autonomia outorgada evidencia a margem de liberdade e de criação da qual o trabalhador é despojado. A situação mostra-se sob uma dimensão paradoxal: um processo permanente de busca de autonomia real por parte dos trabalhadores que se vêem, finalmente, despojados pela outorga de uma autonomia pré-definida. No entanto, a sua dimensão paradoxal vai ainda mais longe: se a autonomia outorgada é uma pseudoliberdade, ela também é um enriquecimento simbólico do trabalho pelo aumento de autonomia real, de criatividade e iniciativa. A questão central, no entanto, não pode diluir-se neste paradoxo: a busca de autonomia situa-se fora da lógica econômica e dentro de uma lógica de valores e de conquista de sentido, enquanto a autonomia outorgada inscreve-se em uma lógica instrumental. 


\section{Referências}

ARENDT, Hannah. A condição humana. Rio de Janeiro: Forense Universitária, 1991.

CASTEL, Robert. Les métamorphoses de la question sociale. Paris: Fayard, 1995.

DEJOURS, Christophe. Coopération et construction de l'identité en situation de travail. Futur antérieur, n. 16, p. 41-52, 1993.

DEJOURS, Christophe. Analyse psychodynamique des situations de travail et sociologie du language. In: BOUTET, Josiane (org.). Paroles au travail. Paris: I'Harmattan,1995.

DURAND, Jean-Pierre. La chaîne invisible. Paris: Seuil, 2004.

FRIEDMANN, Georges. O trabalho em migalhas. São Paulo: Perspectiva, 1972.

GORZ, André. Métamorphoses du travail et quête de sens. Paris: Galilée, 1988.

GORZ, André. Misères du présent, Richesse du possible. Paris: Galilée, 1997.

MARTIN, Dominique. Démocratie industrielle. Paris: PUF, 1994.

MEDA, Dominique. Le travail, une valeur en voie de disparition. Paris: Aubier, 1995.

PERRET, Bernard. Fin de la valeur travail? Esprit, n.1, 1988.

PERRET, Bernard. L'avenir du travail. In: BOISARD, Pierre et al. Le travail, quel avenir? Paris: Gallimard, 1997.

PERRET, B. \& ROUSTANG, G. L'économie contre la société. Paris: Seuil, 1993.

REYNAUD, J.-D. Les règles du jeu, l'action collective et la régulation sociale. Paris: Armand Colin, 1993.

ROSENFIELD, Cinara L. L'automie comme norme et le rapport au travail; une étude comparative France-Brésil. Lille: ANRT, 2003a. 
Sociologias, Porto Alegre, ano 6, no 12, jul/dez 2004, p. 202-227

ROSENFIELD, Cinara L. Autonomia outorgada e relação com o trabalho: liberdade e resistência no trabalho na indústria de processo. Revista Sociologias, Programa de Pós-Graduação em Sociologia, IFCH/UFRGS, ano 5, no10, p. 350-378, jul/ dez 2003b.

TERSSAC, Gilbert de. Autonomie dans le travail. Paris: PUF, 1992.

ZARIFIAN, Philippe. La nouvelle productivité. Paris: L'Harmattan, 1990.

ZARIFIAN, Philippe. Travail et communication; essai sociologique sur le travail dans la grande entreprise industrielle. Paris: PUF, 1996.

Recebido: 17/05/2004

Revisado: 16/06/2004 Aceite final: 25/06/2004 


\section{Resumo}

O objetivo deste trabalho é discutir o significado da autonomia outorgada enquanto corolário organizacional de uma demanda de mobilização subjetiva. O trabalho vive a contradição entre a apologia da autonomia e uma organização do trabalho crescentemente normalizada, onde ser autônomo é a regra. O conceito de autonomia no trabalho lança mão de duas questões: a dimensão operacional e a dimensão identitária. A transformação do trabalho em um bem cuja possessão exige sacrifícios e a transformação do emprego em um privilégio culminam em uma sujeição da própria pessoa do trabalhador, sem se colocar realmente a questão da reapropriação do trabalho, o que a priori acompanharia a autonomia no trabalho. A questão central, no entanto, não pode se diluir neste paradoxo entre autonomia real e autonomia outorgada: a busca de autonomia situa-se fora da lógica econômica e dentro de uma lógica de valores e de conquista de sentido, enquanto que a autonomia outorgada inscreve-se em uma lógica instrumental.

Palavras-chave: normalização do trabalho, autonomia outorgada, ganhos simbólicos, lógica instrumental. 